\title{
Evaluation of the Antibacterial Potential of Traditional Medicinal Plants against Bacteria Isolated from Dental Caries
}

\author{
Sonali Ambulkar ${ }^{1 *}$ (D), Vidya Tale ${ }^{1}$ (D) and Shobha Khilari² \\ ${ }^{1}$ Rajiv Gandhi Institute of IT \& Biotechnology, Bharati Vidyapeeth (Deemed to be University), \\ Pune - 411 046, Maharashtra, India. \\ ${ }^{2}$ Bharati Vidyapeeth College of Ayurved, Pune - 411 046, Maharashtra, India.
}

\begin{abstract}
Dental caries are one of the leading infectious microbial diseases globally. Streptococcus species are the predominant causative agents for the formation of dental caries. Various antibiotics have been reported for the treatment of dental caries in humans. However, owing to the increasing evidence of microbial resistance, there is a need to develop safe and effective alternative treatments for infections. Traditional medicinal plants and their bioactive products have been explored worldwide for the treatment of various diseases and infections. These plants have great potential for creating novel medications without any side effects. The present study aimed to elucidate the antibacterial potential of medicinal plants against biofilm-forming bacteria from dental caries. Bacteria from dental caries were isolated and identified using $16 \mathrm{~S}$ rRNA sequencing technique and the predominant bacterial isolates were Streptococcus mutans (MH889143), Enterococcus faecalis (MH793461), Rothia dentocariosa (MH824681), and Streptococcus anginosus (MH889145). The antibacterial potential of seventeen medicinal plants was determined against these bacterial isolates using the agar well diffusion method. The aqueous extracts of Moringa oleifera, Ficus benghalensis, Ficus racemosa, Ficus religiosa, Senegalia catechu, Pistacia integerrima, and Quercus infectoria showed significant inhibition against all bacterial isolates. Pistacia integerrima and Quercus infectoria showed the maximum inhibition. The present study confirmed that traditional medicinal plants could be helpful for the treatment of oral and dental ailments.
\end{abstract}

Keywords: Dental caries, Medicinal plants, Antibacterial activity

*Correspondence: sonaliambulkar2@gmail.com

(Received: March 09, 2021; accepted: June 22, 2021)

Citation: Ambulkar S, Tale V, Khilari S. Evaluation of the Antibacterial Potential of Traditional Medicinal Plants against Bacteria Isolated from Dental Caries. J Pure Appl Microbiol. 2021;15(3):1204-1210. doi: 10.22207/JPAM.15.3.10

(C) The Author(s) 2021. Open Access. This article is distributed under the terms of the Creative Commons Attribution 4.0 International License which permits unrestricted use, sharing, distribution, and reproduction in any medium, provided you give appropriate credit to the original author(s) and the source, provide a link to the Creative Commons license, and indicate if changes were made. 


\section{INTRODUCTION}

Dental caries are a prevalent dental disease worldwide. The World Health Organization, reported that $60 \%-90 \%$ of school-going children and more than $90 \%$ of adults suffer from dental cavities leading to the formation of caries. Therefore, dental caries is a major public health problem globally ${ }^{1}$

In the oral cavity, different microbial species known as oral microbiota, are found. Over 750 species of microorganisms have been reported in the oral cavity ${ }^{2}$. The formation of dental caries is due to acidogenic and aciduric gram-positive bacteria that metabolize sucrose to organic acid, which dissolves the calcium phosphate in teeth resulting in tooth decay ${ }^{3}$.

Dental caries is a biofilm-mediated infection caused by predominant bacteria such as Streptococcus spp., Lactobacillus, Rothia dentocariosa, and Actinomyces spp. These cariogenic oral bacteria attach themselves to the tooth surface resulting in the formation of a biofilm, which restricts the penetration of drugs ${ }^{4}$.

Various antibiotics have been reported to prevent the formation of dental plaque and caries. However, antibiotic resistance is a major health issue worldwide. Therefore, there is a need to explore safe and alternative therapies for combating infection. Medicinal plants are considered a more suitable, safe, and cost-effective alternative to synthetic medicines ${ }^{5}$.

Medicinal plants are capable of producing a large number of secondary metabolites such as tannins, terpenoids, alkaloids, and flavonoids that possess antimicrobial properties ${ }^{6}$. Recently, there has been increasing interest in the extraction of biologically active compounds from plant species for various therapeutic applications. Plant extracts are an important source of biologically active compounds, making them effective alternatives to routinely used drugs ${ }^{7}$. Many plants have been reported in Ayurveda, whose potential is still unexplored. Therefore, the present investigation aimed to evaluate the antibacterial potential of the aqueous extract of traditional medicinal plants against bacteria isolated from dental caries.

MATERIALS AND METHODS

Preparation of plant aqueous extracts
Table 1. Medicinal plants used for the study

\begin{tabular}{lll}
\hline $\begin{array}{l}\text { Sr. } \\
\text { No. }\end{array}$ & Medicinal Plant & $\begin{array}{l}\text { Part of plant used } \\
\text { for the study }\end{array}$ \\
\hline 1 & Moringa oleifera & Seed \\
2 & Achyranthes aspera & Bark \\
3 & Ficus benghalensis & Bark \\
4 & Ficus racemosa & Bark \\
5 & Ficus religiosa & Bark \\
6 & Senegalia catechu & Bark \\
7 & Bauhinia variegata & Bark \\
8 & Pistacia integerrima & Galls \\
9 & Butea monosperma & Seed \\
10 & Pterocarpus marsupium & Bark \\
11 & Aegle marmelos & Bark \\
12 & Solanum xanthocarpum & Bark \\
13 & Terminali aarjuna & Bark \\
14 & Momordi cacharantia & Bark \\
15 & Nigella Sativa & Seed \\
16 & Quercus infectoria & Galls \\
17 & Citrullus colocynthis & Bark \\
\hline
\end{tabular}

The different plant materials used in Ayurveda and traditional system of medicine were collected and authenticated in collaboration with the College of Ayurved, Bharati Vidyapeeth, Pune, and Agharkar Research Institute, Pune, respectively. Selected plants were washed with sterile distilled water and dried in shade. Each dried plant material was ground into a fine powder. Plant extracts were prepared by dissolving $1 \mathrm{~g}$ of dried plant in $25 \mathrm{~mL}$ sterile distilled water, boiled on slow heat for $5 \mathrm{~min}$ and then filtered through Whatman filter paper. Plant extracts were stored in a small bottle at $5^{\circ} \mathrm{C}$ until further use.

\section{Antibacterial activity of the plant extracts} Isolation and characterization of bacterial isolates

Oral samples collected from dental caries using sterile swabs were spread onto Mitis Salivaris Agar (MSA) medium and incubated at $37^{\circ} \mathrm{C}$ for 48 h. Random colonies were selected and transferred to fresh Mitis Salivaris Agar medium. Purified bacterial colonies were identified using 16S rRNA sequencing. The sequences were searched for homology using BLAST. The sequences were submitted to GenBank for assigning accession numbers.

\section{Antibacterial assay}

Bacterial isolates were inoculated into brain heart infusion broth and incubated overnight 
Ambulkar et al. | J Pure Appl Microbiol | 15(3):1204-1210 | September 2021 | https://doi.org/10.22207/JPAM.15.3.10

Table 2. Antimicrobial activity (zone of inhibition, $\mathrm{mm}$ ) of various plant extracts against isolated oral pathogens

\begin{tabular}{|c|c|c|c|c|c|}
\hline \multirow[b]{2}{*}{$\begin{array}{l}\text { Sr. } \\
\text { No }\end{array}$} & \multirow[b]{2}{*}{ Plant extracts used } & \multicolumn{4}{|c|}{ Zone of inhibition in $\mathrm{mm}$ against the bacteria } \\
\hline & & $\begin{array}{l}\text { S. mutans } \\
\text { Mean } \pm \text { S.D. }\end{array}$ & $\begin{array}{l}\text { E. faecalis } \\
\text { Mean } \pm \text { S.D }\end{array}$ & $\begin{array}{l}\text { R. dentocariosa } \\
\text { Mean } \pm \text { S.D }\end{array}$ & $\begin{array}{l}\text { S. anginosus } \\
\text { Mean } \pm \text { S.D }\end{array}$ \\
\hline 1 & Moringa oleifera (seeds) & $17.00 \pm 1.41$ & $15 \pm 1.41$ & $16.50 \pm 0.70$ & $17.00 \pm 2.82$ \\
\hline 2 & Achyranthes aspera (bark) & $8.00 \pm 1.41$ & $6.00 \pm 8.48$ & No zone & No zone \\
\hline 3 & Ficus benghalensis (bark) & $17.50 \pm 2.12$ & $13.50 \pm 2.12$ & $13.50 \pm 2.12$ & $14.00 \pm 1.41$ \\
\hline 4 & Ficus racemosa (bark) & $14.00 \pm 1.41$ & $14 \pm 1.41$ & $15.00 \pm 1.41$ & $15.50 \pm 2.12$ \\
\hline 5 & Ficus religiosa (bark) & $17.50 \pm 2.12$ & $13.00 \pm 2.82$ & $12.50 \pm 0.70$ & $8.50 \pm 0.70$ \\
\hline 6 & Senegalia catechu (bark) & $17.00 \pm 1.41$ & $13.50 \pm 0.70$ & $6.50 \pm 9.19$ & $12.00 \pm 1.41$ \\
\hline 7 & Bauhinia variegata (bark) & $15.00 \pm 1.41$ & $10.50 \pm 2.12$ & $12.00 \pm 1.41$ & $13.00 \pm 1.41$ \\
\hline 8 & Pistacia integerrima (gall) & $26.00 \pm 1.41$ & $25.50 \pm 0.70$ & $23.00 \pm 1.41$ & $19.50 \pm 3.53$ \\
\hline 9 & Butea monosperma (seed) & No zone & No zone & No zone & No zone \\
\hline 10 & Pterocarpus marsupium (bark) & $11.50 \pm 0.70$ & $6.00 \pm 8.48$ & $7.00 \pm 9.89$ & $12 \pm 1.41$ \\
\hline 11 & Aegle marmelos (fruit) & No zone & No zone & No zone & No zone \\
\hline 12 & Solanum xanthocarpum (bark) & No zone & No zone & No zone & No zone \\
\hline 13 & Terminalia arjuna (bark) & $13.00 \pm 1.41$ & $11.00 \pm 2.82$ & $10.50 \pm 0.70$ & $5.00 \pm 7.07$ \\
\hline 14 & Momordica charantia (seed) & No zone & No zone & No zone & No zone \\
\hline 15 & Nigella sativa (seed) & No zone & No zone & No zone & No zone \\
\hline 16 & Quercus infectoria (gall) & $23.00 \pm 1.41$ & $19.00 \pm 7.07$ & $17 \pm 1.41$ & $18.00 \pm 2.82$ \\
\hline \multirow[t]{4}{*}{17} & Citrullus colocynthis (bark) & No Zone & No zone & No zone & No zone \\
\hline & $0.2 \% \mathrm{CHX}$ (control) & $18.60 \pm 0.65$ & $19.00 \pm 0.91$ & $21.83 \pm 0.57$ & $24.33 \pm 0.27$ \\
\hline & F-Value & 38.2 & 7.31 & 13.71 & 13.91 \\
\hline & P-Value* & $<0.001+$ & $<0.001 \dagger$ & $<0.001+$ & $<0.001+$ \\
\hline
\end{tabular}

P-value derived from ANOVA Test; $\uparrow$ significant at $\mathrm{p}<0.05$, zone of inhibition in $\mathrm{mm}$. Values are mean of duplicate readings (mean \pm S.D)

at $37^{\circ} \mathrm{C}$. The antibacterial activity of the aqueous plant extract was determined using a modified agar well diffusion assay. Bacterial culture $(100 \mu \mathrm{L}$, approximately $10^{6} \mathrm{CFU} / \mathrm{mL}$ ) was spread uniformly onto Mueller-Hinton agar medium. Aqueous extracts of plants $(100 \mu \mathrm{L})$ were added to the wells. Chlorhexidine was used as a control. Plates were maintained at $37^{\circ} \mathrm{C}$ for $24 \mathrm{~h}$. Antibacterial activity was checked by the presence of a zone of inhibition $^{8}$.

Determination of minimum inhibitory concentration (MIC)

The MIC was determined using the broth dilution method using 96-well microtiter plates. In each well, $100 \mu \mathrm{L}$ of BHI broth, $50 \mu \mathrm{L}$ of overnight bacterial culture, and $50 \mu \mathrm{L}$ of the stock solution of each extract (concentration $1 \mathrm{mg} / \mathrm{mL}$ ) was added. Serial dilution was performed using a micropipette up to the $10^{\text {th }}$ well. Control wells were prepared with the culture medium, broth suspension, and the extract of each plant. The plates were incubated at $37^{\circ} \mathrm{C}$ for $24 \mathrm{~h}$. The MIC value of the plant extract was evaluated as the lowest concentration that completely inhibited bacterial growth after $24 \mathrm{~h}$ of incubation ${ }^{9}$.

\section{Statistical analysis}

The means and standard deviations were calculated for each sample. Analysis of variance (ANOVA) was used to assess the statistical significance of the differences between the control and the samples treated with each extract. Differences were considered significant at $p<0.05$.

\section{RESULTS}

\section{Identification of isolated bacteria}

The random bacteria colonies isolated on Mitis Salivaris Agar were identified using 16S rRNA sequencing and were found to be Streptococcus mutans (MH889143), Enterococcus faecalis (MH793461), Rothia dentocariosa (MH824681), and Streptococcus anginosus (MH889145). The accession numbers mentioned in brackets were assigned after submitting the sequences to GenBank, NCBI. 


\section{Antibacterial assay}

The antibacterial potential of medicinal plants was evaluated according to their zone of inhibition and compared to that of $0.2 \%$ chlorhexidine used as a standard. Seventeen plants were screened for their antibacterial potential.
Seven plants, namely, Pistacia integerrima, Quercus infectoria, Moringa oleifera, Ficus religiosa, Ficus benghalensis, Ficus racemosa, and Senegalia catechu exhibited significant antibacterial activity. The maximum zone of inhibition against the dental bacterial isolates was

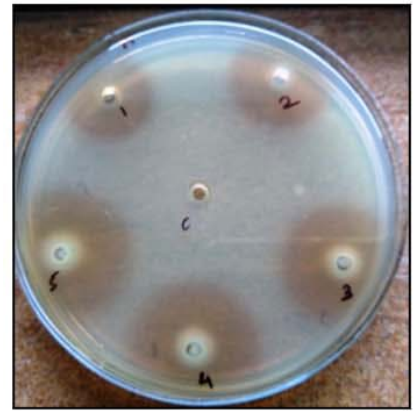

Pistacia integerrima (Gall)

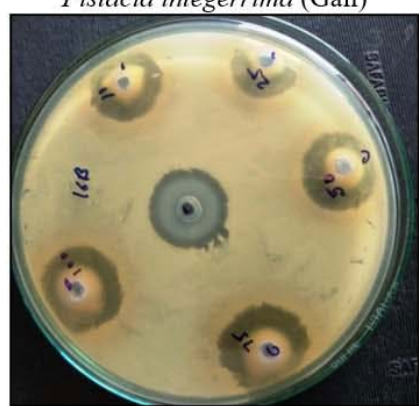

Ficus racemosa (Bark)

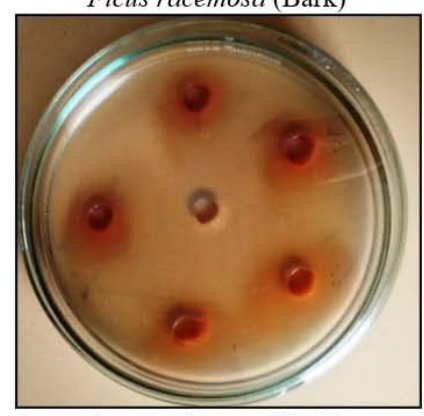

Ficus religiosa (Bark)

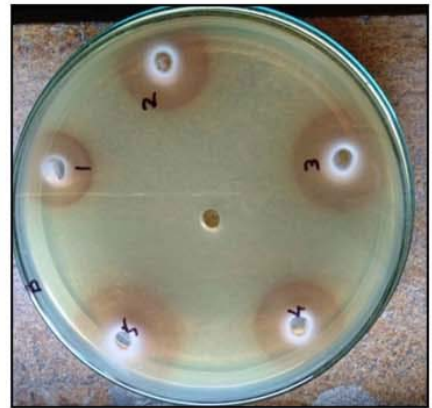

Quercus infectoria (Gall)

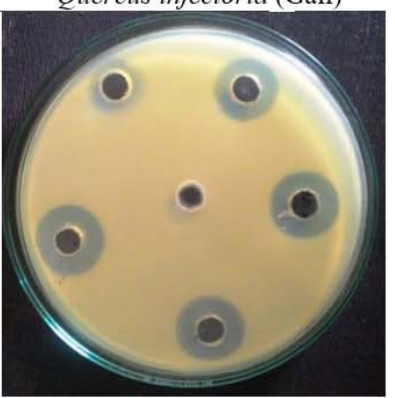

Moringa oleifera $($ Seed)

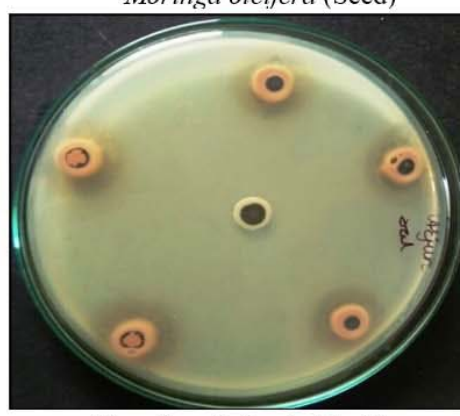

Ficus benghalensis (Bark)

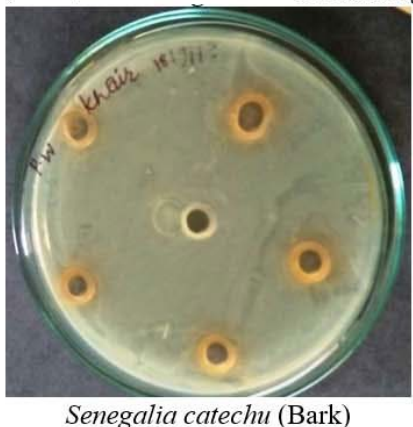

Senegalia catechu (Bark)

Fig. 1. Antimicrobial activity of various plant extracts using agar well diffusion method 
Table 3. Minimum inhibitory concentration (MIC values of potential plant extracts against isolated bacteria

\begin{tabular}{lcccc}
\hline & \multicolumn{4}{c}{ Minimum inhibitory concentration $(\mu \mathrm{g} / \mathrm{ml})$} \\
Plants extract & S. mutans & E. faecalis & R. dentocariosa & S. anginosus \\
\hline Pistacia integerrima & 1.33 & 1.27 & 1.89 & 1.58 \\
Quercus infectoria & 1.57 & 2.53 & 2.50 & 2.36 \\
Moringa oleifera & 0.83 & 1.07 & 1.27 & 1.25 \\
Ficus religiosa & 0.73 & 0.81 & 0.93 & 1.16 \\
Ficus benghalensis & 0.81 & 0.86 & 1.02 & 1.14 \\
Ficus racemosa & 0.96 & 1.09 & 0.88 & 1.19 \\
Senegalia catechu & 0.90 & 0.80 & 0.77 & 1.04 \\
O.2\% CHX & 0.40 & 0.57 & 0.78 & 1.25 \\
\hline
\end{tabular}

observed in $P$. integerrima and $Q$. infectoria.

Four plants, namely Achyranthes aspera,

Bauhinia variegata, Pterocarpus marsupium, and Terminalia arjuna showed moderate antibacterial activity. Six plants, Butea monosperma, Aegle marmelos, Solanum xanthocarpum, Momordica charantia, Nigella sativa, and Citrulluscolocynthis did not show any inhibitory effect on oral bacteria.

The antibacterial activity potential of all the aqueous extracts of medicinal plants evaluated against the four isolated bacteria is summarized in Table 2.

\section{Determination of minimum inhibitory concentration (MIC)}

The MIC was determined for the seven plant extracts that showed significant antibacterial activity. The MIC values of the different plant extracts against the isolated bacteria are presented in Table 3. The inhibitory effects, expressed as the MIC values, of the seven plant extracts on bacterial growth were in the range of $<0.73$ to $>2.53 \mu \mathrm{g} /$ $\mathrm{mL}$.

\section{DISCUSSION}

The present study aimed to screen seventeen traditional medicinal plants against bacterial isolates that are commonly associated with dental caries. Streptococcus mutans, Enterococcus faecalis, Rothia dentocariosa and Streptococcus anginosus were isolated from dental caries samples. These bacteria are reported to play an important role in dental caries because of their ability to form biofilms ${ }^{10}$.

Traditional medicinal plants and plantderived bioactive compounds have been a source of novel drug discovery for various ailments. These could be a safer and cost-effective alternative for the treatment of various bacterial infections and to combat the increasing drug resistance of these bacteria. Microbial growth in biofilms has significantly increased the possibility of survival in the presence of antibiotics. Ayurvedic medicinal plants were explored in the present study. The plants were selected based on their beneficial capability in oral health benefits, as reported in the Charak Samhita ${ }^{11}$. The seventeen aqueous extracts were prepared and checked for antibacterial activity using the agar well diffusion method against S. mutans (MH889143), E. faecalis (MH793461), S. anginosus (MH889145), and $R$. dentocariosa (MH824681). Results showed that seven plants, namely, $P$. integerrima, $Q$. infectoria, M. oleifera, F. religiosa, F. benghalensis, F. racemosa, and S. catechu, exhibited significant antibacterial activity.

The aqueous extracts evaluated in our study showed excellent results with $P$. integerrima galls exhibiting a zone of inhibition of $26.00 \pm$ $1.41 \mathrm{~mm}, 25.50 \pm 0.70 \mathrm{~mm}, 23.00 \pm 1.41 \mathrm{~mm}$, and $19.50 \pm 3.53 \mathrm{~mm}$ against $S$. mutans, E. faecalis, $R$. dentocariosa, and $S$. anginosus, respectively. The maximum antibacterial activity was observed in $P$. integerrima against all the isolated oral bacteria. The excellent antimicrobial activities observed in our study are very significant when compared to those obtained with hot water extracts of $P$. integerrima gall which showed non-significant ( $p$ $>0.05$ ) zones of inhibition of $9 \mathrm{~mm}$ against Bacillus subtilis and Salmonella typhi and of $8 \mathrm{~mm}$ against Enterococcus faecalis, Staphylococcus aureus, and Pseudomonas aeruginosa ${ }^{12}$. 
A previous report suggested the antibacterial potential of $P$. integerrima gall against various bacteria such as Bacillus cereus (zone of inhibition, $20.03 \pm 0.15 \mathrm{~mm}$ ), S. aureus (16.60 $\pm 0.31 \mathrm{~mm}), P$. aeruginosa $(14.60 \pm 0.31 \mathrm{~mm})$, Escherichia coli (11.60 $\pm 0.23 \mathrm{~mm})$, and Klebsiella pneumoniae $(6.60 \pm 0.31 \mathrm{~mm})^{12}$.

The presence of secondary metabolites in the gall of $Q$. infectoria could be responsible for its antibacterial activity against various pathogens. The high tannin content in the galls of $Q$. infectoria has been reported as responsible for its antibacterial activity ${ }^{13}$ studied the antibacterial activity of methanol and acetone extracts of $Q$. infectoria galls against $S$. mutans and observed a zone of inhibition of $22.67 \pm 0.33 \mathrm{~mm}$ and 21.33 $\pm 0.33 \mathrm{~mm}$, respectively. Significant antibacterial activity by aqueous extracts of $Q$. infectoria was observed against the bacteria isolated in our study. In addition to these two prominent plants, five other plants, i.e., $M$. oleifera, $F$. religiosa, $F$. benghalensis, $F$. racemosa, and $S$. catechu exhibited antibacterial potential against the isolated bacteria. The significant inhibition of Streptococcus species and similar antibacterial activities of these plants has been reported previously ${ }^{14,15}$. P. integerrima and $Q$. infectoria showed the most promising results against oral bacterial isolates. It was observed that these plants may contain broad-spectrum antibacterial compounds that could be used for preventive treatments in dental caries.

\section{CONCLUSION}

Traditional Indian medicinal plants have immense antimicrobial potential. The aqueous extracts of $M$. oleifera, $F$. benghalensis, F. racemosa, F. religiosa, S. catechu, P. integerrima, and $Q$. infectoria showed significant antibacterial activity against isolated bacteria which are majorly associated with dental caries. The highest inhibition was shown by $P$. integerrima and $Q$. infectoria. These medicinal plants should be further explored for their potential application in the treatment of oral diseases.

\section{ACKNOWLEDGMENTS}

None.

\section{CONFLICT OF INTEREST}

The authors declare that there is no conflict of interest.

\section{AUTHORS' CONTRIBUTION}

All authors listed have made a substantial, direct and intellectual contribution to the work, and approved it for publication.

\section{FUNDING}

None.

\section{DATA AVAILABILITY}

All datasets generated or analyzed during this study are included in the manuscript.

\section{ETHICS STATEMENT}

Not applicable.

\section{REFERENCES}

1. Dixit LP, Shakya A, Shrestha M, Shrestha A. Dental caries prevalence, oral health knowledge and practice among indigenous Chepang school children of Nepal. BMC Oral Health.2013;13:20. doi: 10.1186/1472-6831-13-

2. Jenkinson HF, Lamont RJ. Oral microbial communities in sickness and in health. Trends Microbiol. 2005;13(12):589-95.doi: 10.1016/j.tim.2005.09.006.

3. Adyanthaya A, Ismail S, Sreelakshmi N. Indian traditional medicinal herbs against dental caries - an unsung past to a bright future. Saudi Journal of Oral and Dental Research. 2016;1(1):1-6.

4. Aas JA, Griffen AL, Dardis SR, et al. Bacteria of dental caries in primary and permanent teeth in children and young adults. J Clin Microbiol. 2008;46(4):1407-1417. doi: 10.1128/JCM.01410-07

5. Balunas MJ, Kinghorn A. Drug discovery from medicinal plants. Life Sciences. 2005;78(5):431-441. doi: 10.1016/j.Ifs.2005.09.012.

6. Mujeeb F, Bajpai P, Pathak N. Phytochemical Evaluation, Antimicrobial Activity, and Determination of Bioactive Components from Leaves of Aegle marmelos. BioMed Res Int. 2014;497606. doi: 10.1155/2014/497606.

7. Katiyar C, Gupta A, Kanjilal S, Katiyar S. Drug discovery from plant sources: An integrated approach. Ayu. 2012;33(1):10-19. doi:10.4103/0974-8520.100295

8. Yim N-H, Jung YP, Cho W-K, et al. Screening of aqueous extracts of medicinal herbs for antimicrobial activity against oral bacteria. Integrative Medicine Research. 2013;2(1):18-24. doi: 10.1016/j.imr.2013.02.002.

9. Klancnik A, Piskernik S, Jersek B, Mozina SS. Evaluation of diffusion and dilution methods to determine the antibacterial activity of plant extracts. J Microbiol Methods. 2010;81(2):121-126. doi: 10.1016/j. mimet.2010.02.004.

10. MacFarlaneTW, Samaranayake LP. Microbiology of dental caries. Clinical Oral Microbiology.2014;3(1):35-50. 
11. Shastri K, Chaturvedi G. Charak Samhita, Vidyotini Hindi commentary Varanasi: Chaukhamba Bharati Academy. 2018;1-2.

12. Khalid A, Waseem A, Saadullah M, et al. Antibacterial activity analysis of extracts of various plants against gram -positive and -negative bacteria. Afr J Pharm Pharmacol. 2011;5(7):887-893.

13. Basri DF, Tan LS, Shafiei Z, Zin NM. In vitro antibacterial activity of galls of Quercus infectoria Olivier against oral pathogens. Evid Based Complement Alternat Med. 2012; 632796.doi: 10.1155/2012/632796

14. Gayathri M, Kannabiran K. Antimicrobial activity of Hemidesmus indicus, Ficus bengalensis and Pterocarpus marsupium roxb. Indian J Pharm Sci. 2009;71(5):578-581. doi: 10.4103/0250-474X.58182

15. Hossain MS, Sayeed MA, Uddin MN. In-vitro antimicrobial activity of methanolic extract of Ficus racemosa Linn. fruits. Journal of Scientific and Innovative Research.2014;3(34):446-449. 